\title{
A empresa e seu ambiente de interação: \\ os limites da Teoria dos Custos de Transação e o alcance da Teoria Institucionalista Evolucionária *
}

\author{
Adriano José Pereira ** \\ Ricardo Dathein ${ }^{* * *}$ \\ Octávio Augusto Camargo Conceição ${ }^{* * * *}$
}

\begin{abstract}
Resumo
Este artigo analisa o significado e a importância das empresas para o desempenho das economias sob a perspectiva de duas vertentes teóricas que apresentam diferentes concepções, ainda que parcialmente complementares: a Nova Economia Institucional (NEI) eo Institucionalismo Evolucionário. Tais diferenças abrangem a compreensão do significado de "instituição" e a forma como se dão as relações dos indivíduos com as instituições e dessas entre si. Considerando a empresa como instituição e unidade de análise, a Teoria Institucionalista Evolucionária incorpora os conceitos de governança e de custos de transação à sua perspectiva analítica com ênfase em seus aspectos dinâmicos. Explicita-se, assim, o papel das empresas no desenvolvimento econômico em sua dupla condição: instituições e agentes de inovação.
\end{abstract}

Palavras-chave: Instituições; Custos de transação; Inovação; Teoria da firma; Desenvolvimento econômico.

\section{Abstract \\ Firms and their interaction environment: the limitations of the Transaction Cost Theory and the reach of the Evolutionary Institutionalist Theory}

This article analyzes the meaning and importance of firms to the performance of economies from the perspective of two representative theoretical issues, which constitute different views, though partially complementary: the New Institutional Economics (NIE) and the Evolutionary Institutionalist Theory. Such differences include the understanding of the meaning of 'institution' and the form of relations between individuals and institutions and those between them. Considering the firm as an institution and the unit of analysis, the Evolutionary Institutionalist Theory incorporates the concepts of governance and transaction costs to their analytic perspective, emphasizing its dynamic aspects. The role of firms in economic development becomes explicit with its double condition: institutions and innovation actors.

Keywords: Institutions; Transaction costs; Innovation; Theory of the firm; Economic development. JEL B52, D23, O12.

* Trabalho recebido em 21 de março de 2011 e aprovado em 28 de abril de 2013.

${ }^{* *}$ Professor adjunto do Departamento de Ciências Econômicas e do Programa de Pós-Graduação em Economia e Desenvolvimento ( $\underline{\mathrm{PPGE} \& D}$ ) da Universidade Federal de Santa Maria (UFSM), Santa Maria, RS, Brasil. E-mail: adrianoeconomia@ufsm.br.

**** Professor associado do Departamento de Economia e Relações Internacionais e do Programa de PósGraduação em Economia (PPGE) da Universidade Federal do Rio Grande do Sul (UFRGS), Porto Alegre, RS, Brasil. E-mail: ricardo.dathein@ufrgs.br.

***** Professor do Programa de Pós-Graduação em Economia (PPGE) da Universidade Federal do Rio Grande do Sul (UFRGS), Porto Alegre, RS, Brasil. E-mail: octavio@fee.tche.br. 


\section{Introdução}

A literatura institucionalista tem apontado, ainda que com diferentes enfoques, a estreita relação entre crescimento econômico e mudança institucional. Decorre da natureza dessa relação a necessidade de compreensão dos mecanismos que contribuem para as mudanças institucionais e estruturais que afetam as diferentes trajetórias de desenvolvimento das economias.

Seja como agente econômico (na Teoria dos Custos de Transação - TCT), seja como instituição (na Teoria Institucionalista Evolucionária), a empresa constituiu-se em um objeto de estudo a partir do qual têm sido analisados os motivos e limites de suas ações. Essas duas perspectivas enfatizam a importância da empresa em suas relações com os ambientes externo (mercado) e interno enquanto elementos centrais para o entendimento do desempenho das diferentes economias em termos agregados.

Os mecanismos que contribuem tanto para a mudança institucional quanto para as condições estruturais que interferem no processo de desenvolvimento de uma determinada economia ao longo de sua trajetória são intrínsecos às atividades produtiva, comercial, inovativa etc. das empresas. Tendo em vista que a combinação de diferentes formas de inovação (tecnológicas, organizacionais e institucionais) é fundamental para o desempenho das economias, as empresas tomam posição de destaque na Teoria Institucionalista Evolucionária, que engloba neo-institucionalistas herdeiros do "velho" institucionalismo (Hodgson, 1993) e neo-schumpeterianos (evolucionários).

A "economia institucional" abrange uma ampla gama de visões e autores, o que, em grande medida, explica os motivos pelos quais não se tenha chegado a um consenso a respeito do significado, da abrangência e da importância das instituições para o desempenho das economias (Hodgson, 1994; North, 1994; Samuels, 1995). Por isso, neste artigo, parte-se de um entendimento amplo ${ }^{1}$ a respeito do significado de "instituição", que, de certa forma, contempla diferentes correntes teóricas, para uma caracterização mais específica acerca dos mecanismos institucionais que promovem o desenvolvimento econômico, como os aspectos associados ao aprendizado organizacional, próprios das "instituições empresariais" (Langlois; Robertson, 1995).

O objetivo principal deste artigo é caracterizar o significado e a importância das empresas para o desempenho das economias, sob a perspectiva de duas "vertentes teóricas" representativas que adotam diferentes concepções, embora, em parte, complementares a respeito do tema: a Nova Economia Institucional (NEI) e a Teoria Institucionalista Evolucionária. Tais diferenças vão desde a compreensão do que é

(1) Tal amplitude decorre do fato de que o sentido dado a "instituições" abarca um conjunto de perspectivas analíticas em diferentes áreas do conhecimento (História, Direito, Psicologia, Sociologia, Economia etc.), demonstrando a multidisciplinaridade de seu tratamento. 
uma instituição até a forma como se dão as relações dos indivíduos com as instituições e dessas entre si. Esse contraponto é fundamental para a compreensão do significado e importância das instituições para uma teoria Institucionalista Evolucionária da firma, sobretudo no que se refere às inovações e ao papel transformador da empresa como agente do desenvolvimento econômico.

Seria inapropriado e demasiadamente ambicioso estabelecer, neste artigo, um levantamento sobre a natureza da firma nas várias escolas do pensamento econômico, pois tal levantamento, além de fugir do escopo do que se pretende aqui discutir, tiraria o foco do aspecto central do artigo, qual seja, o nexo e a familiaridade entre as abordagens institucionalistas e evolucionárias.

Entretanto, algumas inferências nesse campo de análise são necessárias, até para tornar mais explícita a importância tanto da contribuição da NEI quanto dos institucionalistas "veblenianos" e sua compatibilidade e convergência com os aportes evolucionários ou neo-schumpeterianos.

Ronald Coase, ao escrever, em 1937, The Nature of the firm, estabeleceu um ponto de ruptura definitivo com a visão de firma neoclássica, inaugurando uma nova abordagem, que, só nos anos 1960, ficou conhecida como Nova Economia Institucional. Tal trabalho somava-se, assim, ao clássico estudo de Hall e Hitch sobre o princípio do custo total, que apregoava que as firmas baseavam suas decisões não na alocação ótima, através do menor custo da racionalidade substantiva, mas em como gerir e administrar os custos totais, que passaram a constituir o princípio organizador da atividade produtiva na firma. Nesse âmbito, ambos os autores rompiam simultaneamente com dois princípios que fundamentavam os pilares da microeconomia neoclássica para a existência da firma. Negavam, de um lado, a firma "representativa" homogênea e racional - na medida em que foi concebida unicamente para minimizar custos de produção - e, de outro, introduziam novos elementos sistêmicos à decisão empresarial ou organizacional de "o que produzir", cujo elenco de escolhas era muito mais amplo e abrangente do que a escolha racional pelo menor custo. A partir daí, o ambiente, as transações e as incertezas inerentes a esse movimento forneceram munição à elaboração de novas teorias organizacionais.

Tal legado substanciou, nos anos 1960, elementos para a constituição da Economia dos Custos de Transação, um desdobramento essencial da NEI. Também deixou para trás a visão otimizadora da firma representativa homogênea, a-histórica e neutra do ponto de vista institucional, para dar sustentação teórica a novos ambientes nos quais as variáveis institucionais e tecnológicas, abaladas sistematicamente por mudanças na estrutura, passaram a ditar as estratégias e as ações empresariais. Temse, então, uma "nova firma", como se verá na sequência. E essa nova dimensão analítica passou a exigir novas teorias, antagônicas à firma representativa, que vêm permitindo avanços nesse campo de pesquisa. 
Sem tentar estabelecer nexos fora desse âmbito, acredita-se que outras visões heterodoxas de firma, como a marxista e a keynesiana, embora não tenham explicitamente por objetivo estabelecer uma "teoria organizacional da firma", comunguem, em vários aspectos, com a abertura conceitual e analítica estabelecida pelos autores aqui discutidos.

A visão marxista de firma, embora não tenha sido concebida para funcionar de modo a garantir eficiência à organização dos mercados, dialoga com vários aspectos institucionais que a relação infraestrutura versus superestrutura preconiza. A interação com o ambiente competitivo impõe, para Marx, rearranjos permanentes no âmbito do processo de trabalho, que geram formas diferenciadas de apropriação do excedente, culminando em novas regularidades sistêmicas de reprodução do capital $^{2}$. Da mesma forma, a tradição pós-keynesiana, centrada na tomada do processo de decisão sob incerteza, leva em conta os aspectos organizacionais do ambiente da firma, que ora obstaculizam, ora viabilizam estratégias de produção em sintonia com o ambiente externo em que ela se encontra indissoluvelmente vinculada. A firma keynesiana não pode ser pensada fora de um ambiente embedded, que as tradições analisadas neste artigo enfatizam. Feitos esses esclarecimentos, discutiremos os elementos centrais das abordagens propostas.

Para tanto, o artigo está dividido em quatro seções, além desta introdução. A primeira seção apresenta os fundamentos teóricos da TCT, na qual o objeto central da análise são os custos de transação, que impõem, em grande medida, os limites às ações empresariais. A segunda seção analisa a perspectiva "institucionalistaevolucionária", em que a empresa é foco da análise, sobretudo no que se refere a seus aspectos inovativos. A terceira seção estabelece um contraponto entre as duas teorias, enfatizando a abrangência da Teoria Institucionalista Evolucionária, que incorpora, embora com ressalvas, os conceitos de custos de transação e de "estrutura de governança" como elementos importantes para a definição das trajetórias empresariais. A última seção faz breves observações sobre uma teoria da firma que considera, explicitamente, a importância dos aspectos institucionais para a mudança econômica.

\section{Instituições e mudança institucional na perspectiva da NEI}

Na perspectiva da NEI, as instituições caracterizam-se por serem restrições, à medida que criam/definem limites para o comportamento dos agentes (indivíduos ou organizações), reduzem a incerteza e servem como guia para a interação humana; assim, as instituições são diferentes dos agentes e das organizações que as criam,

(2) A referência aos estudos da Escola Francesa da Regulação é abundante em análises com esse caráter. Robert Boyer, Benjamin Coriat, Alain Lipietz e Michael Aglietta fornecem importantes contribuições nesse sentido. 
usam e aplicam. Não são exógenas nem neutras e se constituem, ao longo do tempo, em importantes elementos para explicar o desempenho das diferentes economias. Em sentido estritamente econômico, as instituições definem e limitam o conjunto de escolhas dos indivíduos; são as "regras do jogo", ao passo que os indivíduos e as organizações são os "jogadores” (North, 1991, 1993). Em suma, os indivíduos fazem escolhas sob determinada "estrutura institucional" (North, 1993), que tende a se modificar ao longo do tempo.

Para North (1993), qualquer proposta de análise de fatos ocorridos, sejam antigos ou recentes, deve levar em consideração a influência que as instituições exerceram sobre eles. Se, por um lado, as instituições serviriam para criar um ambiente favorável à cooperação, por outro, também poderiam ser fontes de conflitos sociais e distributivos. Dessa forma, as instituições caracterizam-se como estruturas de poder, sejam elas formais ou informais. Segundo North (1994, p. 359), "Institutions form the incentive structure of a society, and the political and economic institutions, in consequence, are the underlying determinants of economic performance". Ainda que estabeleçam uma "estrutura estável", a permanente mudança, aliada à incerteza em relação aos resultados que serão obtidos, leva a que as instituições não sejam, necessariamente, eficientes. Como observa North (1994, p.360), "Institutions are not necessarily or even usually created to be socially efficient"3.

Na concepção de North (2005), a evolução das "trocas pessoais" para as "trocas impessoais", à medida que caracterizaram a ampliação dos mercados, tornaram necessária a criação de instituições políticas, como o Estado, com o fim de assegurar o cumprimento das "regras do jogo".

O objetivo dos criadores das organizações, que consistem nos principais agentes da mudança, é a maximização da riqueza ${ }^{4}$. North (1993, p. 106) associa ao uso do poder político o alcance de tal propósito: “Las organizaciones con fuerza de negociación suficiente usarán la política para alcanzar objetivos cuando el resultado de la maximización en esa dirección excede al resultado de invertir dentro de las limitaciones existentes."Assim, não há como isolar o poder político do econômico numa análise institucionalista; a interdisciplinaridade não permite, ainda que "poder" seja uma variável de difícil mensuração. Não se trata de teleologia, como sugere

(3) Esse ponto também é explorado por Nelson (2002) e pela tradição neo-schumpeteriana, na qual o que importa é a busca incessante de novidades tecnológicas, que encobrem uma gama de inovações, permeadas de incertezas, em que nem sempre o alcançado implica maior eficiência ou otimalidade.

(4) Apesar de rejeitar a maior parte dos pressupostos da "teoria neoclássica", North entende que a análise das instituições é compatível com o individualismo metodológico. "Las instituciones son una creación humana. Evolucionan y son alteradas por humanos; por conseguiente, nuestra teoría debe empezar con el individuo" (North, 1993, p. 16). "El agente del cambio es el empresario individual que responde a los incentivos encarnados en el marco institucional" (North, 1993, p. 110). 
Williamson (1995), pois poder (de mercado, entre outros) é uma variável importante para explicar o desempenho das economias (North, 1993; 1999).

Conforme North (1993), existe uma tendência à ocorrência de mudanças institucionais ao longo do tempo, com a alteração de regras (formais e informais) que são determinadas, em primeira instância, pela mudança de comportamento dos indivíduos. Como ressalva, o autor explica que as regras informais podem ter dificuldade de adaptação às novas regras formais. Nesse caso, as mudanças institucionais não costumam ser simples nem rápidas. O processo de evolução social é adaptativo, e a mudança é incremental. "La vía de la dependencia significa que la historia importa. No podemos entender las elecciones de nuestros días [...] sin trazar la evolución incremental de lasinstituciones." (North, 1993, p. 131). Por esse motivo, as instituições não podem nem devem simplesmente ser "transplantadas", mas sim construídas.

Dessa forma, a análise da trajetória de cada sociedade deve ser feita a partir de uma abordagem histórica para que se possa compreender os motivos pelos quais alguns países progrediram (institucional e economicamente) enquanto outros não. Para North (1993), as grandes mudanças históricas (como as da sociedade agrícola para a industrial) se dão a partir das transformações institucionais (criação, adaptação e evolução). O autor entende que instituições "eficientes" contribuem positivamente para o desempenho das economias, ao passo que instituições "ineficientes" contribuem para o seu atraso ${ }^{6}$.

Path dependence implica mudanças contínuas e incrementais numa condição de incerteza em relação ao futuro. Nesse sentido, ainda que o passado não determine o futuro, ele condiciona os seus rumos à medida que os agentes realizam escolhas ao longo do tempo. A maior ou menor eficiência das instituições em relação ao crescimento econômico está estreitamente condicionada por tais escolhas ${ }^{7}$. Como observa o autor: "Time as it relates to economic and societal change is the dimension in which the learning process of human beings shapes the way institutions evolve." (North, 1994, p. 359-360). Williamson (2000) observa que há unanimidade entre as diferentes abordagens institucionalistas em relação ao reconhecimento de que as

(5) A forma como se definiram e se sustentaram os direitos de propriedade, ao longo da história do capitalismo, nos mais diversos países, é um claro exemplo da importância do poder como uma variável política e econômica fundamental. Seus efeitos sobre as instituições capitalistas são mensuráveis, ainda que o poder, em si, não o seja. O uso do poder econômico e político é uma prerrogativa institucional.

(6) Para Matthews (1986), importante representante da NEI, a mudança institucional está sujeita a três características que podem produzir random walk: soluções do tipo dilema do prisioneiro, que tendem a diminuir quando aumenta a frequência das interações; inércia das instituições, inerente a direitos de propriedade, convenções e garantia de autoridade (que pode ser positiva para o crescimento econômico); e complexidade das instituições, que se inclina a reforçar a inércia.

(7) Nesse ponto, North (1993, p. 16) relaciona a análise das instituições à teoria neoclássica: “Definir las instituciones como las limitaciones que los humanos se imponen a sí mismos convierte esta definición en complementaria a la elección del enfoque teórico de la teoría económica neoclásica." 
instituições importam, ou seja, condicionam e afetam diretamente as mudanças em uma sociedade. O que diferencia a NEI, conforme o autor ${ }^{8}$, é que ela trata dos fatores determinantes da construção das instituições e da mudança institucional como sendo passíveis de análise com uso de instrumentais da teoria econômica ${ }^{9}$.

Em uma tentativa de estabelecer uma hierarquia da mudança, Williamson (2000) propõe que as instituições econômicas sejam analisadas a partir de "quatro níveis de análise social", conforme a Figura 1. As setas (de cima para baixo) indicam que há conexão entre os níveis superior e inferior, em que o primeiro impõe restrições ao segundo, ao passo que as setas pontilhadas (de baixo para cima) indicam que há um feedback entre os níveis inferior e superior, demonstrando as interconexões do sistema em seu conjunto. Desse modo, a importância das instituições, e da mudança institucional, seria compreendida a partir desses quatro níveis de análise interligados ${ }^{10}$.

Figura 1

Hierarquia das mudanças das instituições econômicas, segundo Williamson

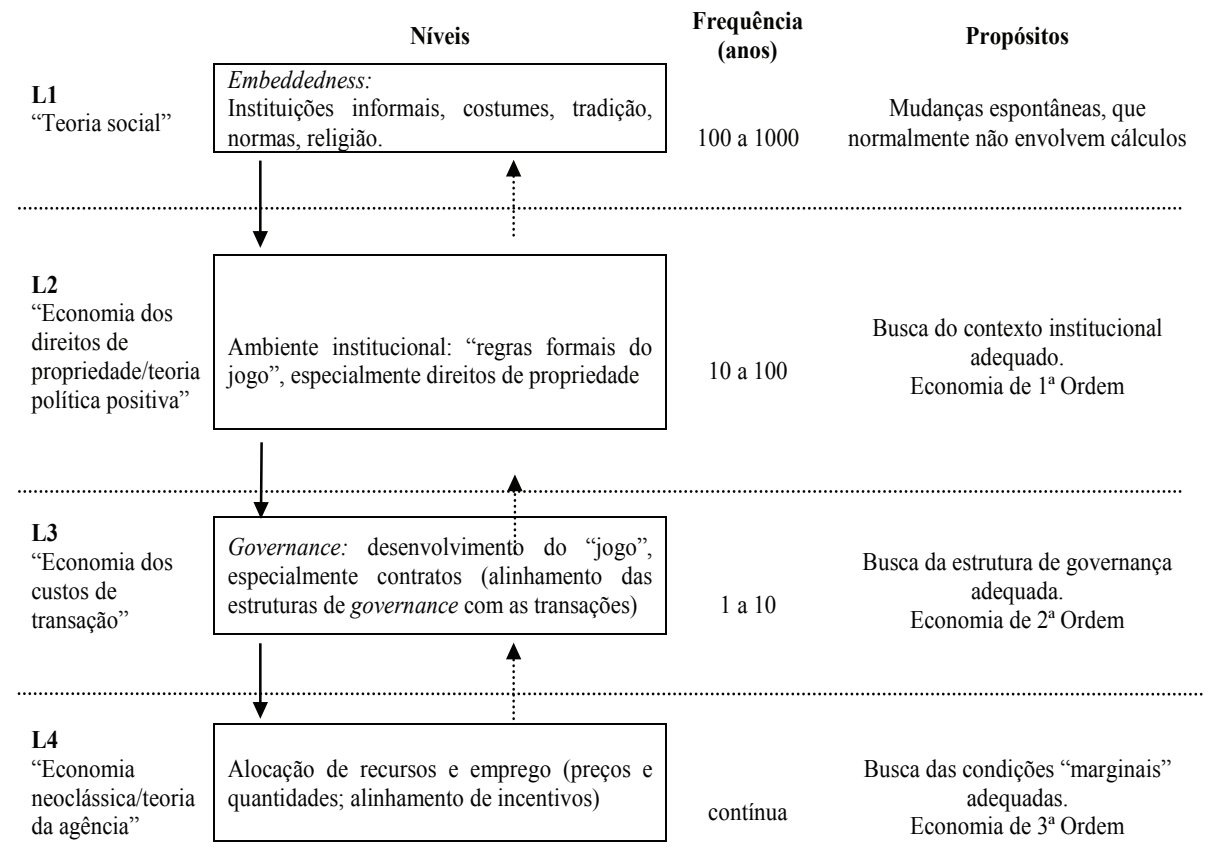

Fonte: Adaptada de Williamson (2000, p. 597).

(8) Williamson (2000) utiliza, como suporte, as proposições feitas por Matthews (1986).

(9) De fato, essa não é uma prerrogativa da NEI, como será visto, posteriormente, na seção2.

(10) Nesse modelo, Williamson deixa clara a busca pela teorização aliada à necessidade de mensuração das variáveis econômicas, especificamente no que se refere ao tempo da mudança. Como observa o autor, "Formalization is vital to a progressive research agenda, but it sometimes comes at a cost" (Williamson, 2000, p. 604). 
O primeiro nível (L1) refere-se a normas, costumes, tradição, religião etc., cujas instituições são informais (espontâneas) e se modificam muito lentamente (mais de um século). Nesse nível, a análise sociológica, bem como a dos historiadores econômicos, seria mais adequada do que a análise com a utilização de instrumentos da teoria econômica para a compreensão da importância e do processo de mudança institucional.

O segundo nível (L2) trata do "ambiente institucional", em que, às regras informais, somam-se as formais, e o processo de mudança institucional compreenderia um intervalo de tempo inferior ao do primeiro nível (entre uma década e um século). É nesse nível de análise que surge a importância das organizações (Governo, Justiça, burocracia etc.) e a disputa pelo poder, que leva à necessidade do uso de regras formais para manter a ordem (reduzir a incerteza, aumentar a eficiência econômica e garantir os direitos de propriedade). É importante ressaltar que mudanças nas regras formais não implicam, necessariamente, mudanças nas regras informais, dado que estas estão baseadas em aspectos comportamentais "enraizados" (embedded), cujo processo de mudança costuma ser mais lento e, por isso, associado ao primeiro nível (L1).

No segundo nível, ocorre a formalização das "regras do jogo", tornando os direitos de propriedade e o cumprimento dos contratos aspectos fundamentais da mudança institucional. "Going beyond the rules of the game (property) to include the play of the game (contract) was needed." (Williamson, 2000, p. 599) ${ }^{11}$.

No terceiro nível(L3), encontra-se a "governança” (através das organizações), cujo objetivo central é garantir o cumprimento dos contratos, além da manutenção da ordem para a realização de ganhos mútuos. A governança contratual torna-se o foco principal dado o papel que exerce na realização das transações que, por sua vez, são o objeto central da análise da NEI, conforme Williamson (2000). Nesse nível, a possibilidade de reformulação dos contratos em uma determinada estrutura de governança é reexaminada periodicamente (entre um ano e uma década, ou quando findar o contrato).

Por sua vez, o quarto nível(L4) de análise está relacionado à “teoria econômica neoclássica", em que a alocação de recursos tem por objetivo a maximização e no qual as mudanças ocorreriam frequentemente.

Ao centrar sua abordagem nos níveis 2 e 3 (Williamson, 2000) ${ }^{12}$, a NEI analisa o ambiente institucional e as instituições de governança a partir de um

(11) Williamson cita a construção da União Europeia como um exemplo das mudanças institucionais nesse nível.

(12) Conforme Williamson (2000), a análise da NEI concentra-se nos níveis dois e três. Entretanto, Douglass North faz uso frequente do primeiro nível de análise, por vezes considerado como o mais importante para a compreensão do processo de mudança econômica. 
determinado contexto, tratando as "regras do jogo" como uma forma de estabelecer condições para a realização das transações por parte dos "jogadores". Em suma, "regras do jogo" e "jogadores" têm diferentes funções na análise institucionalista da NEI. A importância das escolhas, em determinada "estrutura institucional" (níveis 2 e 3), revela a natureza desse processo.

Cabe ressaltar que o primeiro nível (embeddedness) corresponde a uma série de processos históricos, como a formação dos mercados e dos direitos de propriedade, sobretudo no que se refere ao uso dos mecanismos do Estado, fundamentais para a compreensão das diferentes experiências de desenvolvimento econômico ao longo da história.

\subsection{A transação como unidade de análise ${ }^{13}$}

A partir da concepção do significado de "instituição" e de "mudança institucional", a NEI tem buscado desenvolver sua análise a respeito do desempenho das diferentes economias centrando sua abordagem no conceito de custos de transação; em síntese, a partir da ideia de que existem custos em operações de mercado. Portanto, não basta analisar a órbita da produção para se entender porque as empresas existem e de que forma elas se organizam. Assim, as transações são fundamentais para definir os limites da ação das empresas.

A análise dos custos de transação apresenta algumas especificidades: é uma abordagem microanalítica (trata de questões mais específicas do que a abordagem microeconômica tradicional); desenvolve análise comparativa das instituições; considera a empresa uma estrutura organizacional (diferente da análise dos custos de produção); enfatiza a importância das relações contratuais entre os agentes após a realização dos contratos de forma que se torna fundamental dar relevância ao comportamento desses agentes. Em suma, trata de Economia, Direito e Organizações, considerando a História como necessária para dar uma ideia de processo dinâmico(Williamson, 1989b).

A abordagem dos custos de transação enfatiza a importância das instituições para a análise econômica, tendo em vista que mercados crescentemente incompletos e imperfeitos têm como resultado a ocorrência de maiores custos de transação (North, 2006). Conforme Williamson (1989b, p.136): "The basic transaction cost economics strategy for deriving refutable implications is this: assign transactions [...] to governance structures [...] in a discriminating [...] way."

Segundo o autor (1989a), a compreensão do conceito de custos de transação é fundamental, tendo em vista que fazer economia, no sentido de reduzir custos totais,

(13) Essa perspectiva está explícita, sobretudo, na obra de Williamson e tem, como origem, os textos de Commons (1931) e Coase (1999). 
é considerado, pela NEI, como o problema central da organização econômica ${ }^{14}$, tanto no que se refere aos custos intra quanto aos interempresas. Sendo assim, as transações afetam a forma de organização das empresas, exercendo influência sobre o seu comportamento. Por isso, os custos de transação impõem limites às atividades das empresas.

Para Williamson (1989b), se, por um lado, o mercado é mais eficiente na produção de incentivos e restrições de entraves burocráticos, bem como nos ganhos de escala e de escopo, por outro, a organização interna leva vantagem em relação aos instrumentos de controle. Ainda assim, a reciprocidade constitui-se em uma das formas de ganhos mútuos em que a relação entre comprador e vendedor define mais do que uma transação de compra e venda: estabelece uma relação contratual que envolve custos de transação. Numa tentativa de tornar "operacional" o conceito desenvolvido por Commons (1931) e Coase (1999) ${ }^{15}$, e acrescentando novos elementos à abordagem contratual, Williamson $(1989 b, 1993)$ entende que a empresa, como organização, compreende uma estrutura de "governança" (gestão organizacional da empresa, cujo comportamento é diferenciado diante do mercado). Conforme Williamson (apud Conceição, 2001, p. 111), “[...] as considerações transacionais, não as tecnológicas, são as decisivas para determinar qual o modelo de organização que se há de adotar, em que circunstância e porquê". A questão central para a firma, portanto, passa a ser a decisão de em que momento recorrer ao mercado, considerando-se, sobretudo, os custos de transação.

Um dos aspectos fundamentais para a compreensão da existência dos custos de transação consiste na noção de oportunismo, utilizada por Williamson (1989b, p. 139): "Calculate efforts to mislead, disguise, obfuscate, and confuse are thus admitted. This self-interest-seeking attribute is variously described as opportunism, moral hazard, and agency." De qualquer modo, o oportunismo é compreendido como uma forma de comportamento que também está sujeita a restrições impostas pelas instituições, ainda que transmita a ideia de um comportamento maximizador ${ }^{16}$ por parte dos agentes. Nesse enfoque, as falhas de mercado são produtos da incerteza ${ }^{17}$, mas também da existência de oportunismo e de racionalidade limitada (Simon, 1987) que, por sua vez, também são responsáveis pelos custos de transação.

(14) "[...] el propósito principal y el efecto de las instituciones económicas del capitalismo son el de economizar los costos de transacción" (Williamson, 1989a, p. 27).

(15) Coase (1992, p. 718) reconhece, ainda que com ressalvas, a importância de O. Williamson na tentativa de tornar"operacional" o significado de custos de transação para que esse pudesse ser incorporado à teoria econômica.

(16) Para Espino (1999, p. 41), "El supuesto típico de la conducta económica que asume a los individuos como egoístas y maximizadores se puede mantener siempre y cuando se introduzca el papel de las restricciones institucionales y organizacionales en las elecciones económicas de los individuos."

(17) Conforme North (2005, p. 13), autores como Kenneth Arrow e Robert Lucas têm enfatizado que "theorizing under the condition of uncertainty therefore was not possible [...]". Para North, as pessoas teorizam independentemente da existência de incerteza em relação ao futuro. Compreende-se, nesse caso, que a incerteza não traz prejuízos à teorização, mas sim à predição. 
Assim, a abordagem dos custos de transação proposta por Williamson (1989a) combina a incerteza e a racionalidade limitada com a busca do autointeresse (oportunismo). Nesse sentido, as instituições passam a ter um papel fundamental nas relações entre os agentes para garantir a realização dos contratos (Williamson, 1998). O ambiente institucional (regras do jogo) exerce influência direta sobre a estrutura de "governança" que, por sua vez, afeta os custos de transação. Em suma, as falhas de mercado seriam essencialmente produtos da racionalidade limitada e da busca do autointeresse, que acabam gerando incerteza em relação ao futuro, dependendo da forma como se estabelecem as garantias contratuais (Williamson, 1989b).

Nesse sentido, é fundamental considerar o grau de especificidade dos ativos da empresa (Williamson, 1989a), dado que isso afeta as decisões empresariais entre usar o mercado ou manter as relações internalizadas na estrutura de governança. Ainda que diminuam os custos de produção (a partir da especialização, dos ganhos de escala e de escopo etc.), quanto mais específicos forem os ativos da empresa, maiores tendem a ser os custos de transação; por sua vez, quanto menos específicos os ativos, maiores as possibilidades de uso do mercado como forma eficiente de realização das transações; situação que é favorecida com o aumento da frequência em que se realizam as trocas. Como ressalta Mathews (1986) (baseado na "teoria dos jogos"), a frequência das interações entre os agentes econômicos por meio do mercado favorece a redução dos custos de transação na medida em que melhora a reputação das partes, qualificando a informação e diminuindo o oportunismo. Por sua vez, as instituições mais eficientes (que exercem maior controle sobre o oportunismo) diminuem o grau de incerteza sobre os acontecimentos futuros, atuando na redução dos custos de transação.

Como se pode observar, a abordagem da NEI é essencialmente contratual e organizacional, tendo por finalidade explicar o funcionamento da economia a partir dos custos de transação e da estrutura de governança. A interdisciplinaridade abrange também a História para dar sentido dinâmico à análise econômica, como dito anteriormente.

Por sua vez, North $(1991 ; 2006)$ entende que o conceito de custos de transação pode ser utilizado numa perspectiva bastante ampla, a exemplo do tratamento que é dado ao conceito de instituições. Segundo o autor, a História demonstra que a evolução do comércio deve ser entendida como tendo uma importante relação com a evolução institucional. Desde o comércio bastante limitado (tipo feudal, por exemplo) até o comércio a grandes distâncias, passando pelos âmbitos regional e nacional, a evolução comercial esteve vinculada à especialização, à divisão do trabalho e à criação de novas tecnologias produtivas. A ampliação do comércio também afetou os custos de transação, o que tornou necessária a criação de instituições para garantir a continuidade da expansão daquele à medida que os benefícios se estenderiam muito além da realização de trocas. 
Ao dar ênfase ao conceito de custos de transação, North (1993; 2006) destaca que o empresário está incumbido de fazer escolhas que afetem os custos totais (produção e transação), os quais determinam os preços relativos. Williamson (1989b) apresenta uma proposta semelhante ao tratar da especificidade dos ativos e da decisão do empresário entre produzir internamente (make) ou recorrer ao mercado (buy). Entretanto, como ressaltado anteriormente, este último também concebe um comportamento maximizador por parte dos agentes, ou seja, entende que a escolha é a mais eficiente possível, tendo em vista os fatores condicionantes (restrições).

A despeito do caráter multidisciplinar, a abordagem de Williamson (2000) está centrada na tomada de decisão em um contexto preestabelecido. Não se trata da interação indivíduos/instituições, mas sim da opção dos agentes de economizar nas transações, em busca da eficiência produtiva. Essa eficiência, por sua vez, é pressuposta (nível 4), significando que, ao decidirem entre make or buy, os agentes (maximizadores) incorrem em custos de transação favoráveis à organização, reduzindo, com isso, os custos totais, desde que haja o cumprimento dos contratos.

$\mathrm{Na}$ abordagem de North (1993), as instituições desempenham um papel fundamental na determinação dos custos totais. Portanto, não se trata de tomar os custos de produção como um dado alocativo, conforme sugere Williamson (2000), mas sim de entender que: "El marco institucional afectará costos de transformación y de transacción; estos últimos debido a la conexión directa entre instituciones y los costos de transacción, y los primeros por influir en la tecnología empleada" (North, 1993, p. 88-89).

Conforme North (2005), é fundamental compreender que diferentes tipos de mercados, tanto políticos quanto econômicos, conduzem a diferentes resultados em relação ao desempenho das economias. Nessa interpretação, fica evidente que o poder (político e econômico) tem influência direta sobre o processo de mudança econômica e institucional ao longo do tempo. Assim, os mercados, à exemplo das demais instituições, são construções históricas. O autor extrapola a abordagem dos custos de transação como unidade de análise, propondo uma perspectiva multidisciplinar que vai além da questão contratual e da existência de organizações. Para North, mais importante do que compreender como os mercados e as empresas operam (abordagem típica da microeconomia neoclássica, que exerce forte influência sobre a construção teórica da NEI) é saber como eles se desenvolvem.

\section{Instituições e mudança institucional na ótica institucionalista evolucionária}

Para Nelson (2002), além de Schumpeter, economistas como Adam Smith, Karl Marx e Alfred Marshall caracterizaram-se por abordagens "institucionalistasevolucionárias". No entanto, o predomínio da "teoria econômica neoclássica", ao longo da maior parte do século XX, teria contribuído para que houvesse uma 
separação, fora do mainstream, entre aqueles que, como Commons (1931) e Coase (1999), optaram por uma abordagem institucional da mudança econômica, ao passo que autores como Schumpeter (1997) teriam optado por um enfoque centrado nos aspectos tecnológicos. Separação que passaria a ser desfeita, conforme Nelson (2002), somente no final do século XX.

$\mathrm{Na}$ perspectiva institucionalista evolucionária, considera-se como instituições, em um sentido abrangente, o conjunto de hábitos, costumes, rotinas etc. adotados em um determinado contexto, que exerce efeitos sobre o comportamento dos indivíduos, os quais, ao interagirem com as instituições, acabam produzindo uma trajetória de transformação permanente. Uma instituição é, portanto, o resultado de uma ação coletiva que controla, libera ou amplia a ação individual; em que ocorre interação entre instituições e indivíduos, bem como entre indivíduos através das instituições e destas entre si. Assim como ocorre com os indivíduos, as instituições mudam e se desenvolvem em função dos estímulos derivados das circunstâncias em que se encontram. São "hábitos mentais", ou de pensamento, que orientam a forma de ação dos indivíduos que, por sua vez, contribuem ativamente para o desenvolvimento institucional à medida que afetam, a partir de seus hábitos, o contexto em que se inserem. Portanto, os "hábitos de pensamento" são fundamentais para compreender a atitude dos indivíduos e a mudança institucional (Veblen, 1965).

O entendimento de Hodgson (2006) a respeito do significado de institucionalismo, a exemplo do conceito e dos exemplos de instituições (moeda, linguagem, sistemas de pesos e medidas, normas etc.), além da ênfase nos "hábitos de pensamento" e na perspectiva "evolucionária" da análise, evidencia a necessidade de uma visão holística por parte dessa abordagem, com especial atenção aos aspectos cognitivos que envolvem as relações humanas.

A compreensão de mundo pelo indivíduo passa pela experiência adquirida a partir de suas relações e interações sociais. Desse modo, as teorias baseadas na ação dos indivíduos isoladamente (individualismo metodológico) ${ }^{18}$ negligenciam o fato de que estes estão em constante interação com o ambiente que os cerca. A “evolução social" é justamente o resultado desse processo permanente de interação dos indivíduos a partir e através das instituições (HODGSON, 1998). Esse processo, que trata das instituições como "estruturas socialmente construídas", é resultado do mecanismo de reconstitutive downward causation (Hodgson, 2007) ${ }^{19}$.

(18) Hodgson (2007, p.98) observa que: "The narrow methodological individualist has a problem of infinite regress: attempts to explain each emergent layer of institutions always rely on previous institutions and rules."

(19) The existence of reconstitutive downward causation does not mean that institutions directly, entirely or uniformly determine individual aspirations, merely that there can be significant downward effects. Insofar as institutions lead to regularities of behaviour, concordant habits are laid down among the population, leading to congruent purposes and beliefs. In this way the institutional structure is further sustained (Hodgson, 2007, p. 108). A 'reconstitutive downward causation', por sua vez, indicaria a importância dos indivíduos (no sentido coletivo) para as mudanças institucionais. 
Como ressaltado por Veblen (1965), as instituições do presente são moldadas conforme a influência exercida sobre os indivíduos que, por sua vez, fazem escolhas acerca das instituições que serão adotadas e abandonadas. Portanto, as escolhas são condicionadas pelo ambiente de interação em que as instituições são, ao mesmo tempo, condicionantes e resultantes do processo seletivo.

Por sua vez, as instituições econômicas “[...] são métodos habituais de dar continuação ao modo de vida da comunidade em contato com o ambiente material no qual ela vive" (Veblen, 1965, p. 182). Nesse sentido (influenciado por Karl Marx), Veblen (1965) considera que a forma como a sociedade se organiza para produzir suas condições materiais de existência tem forte influência sobre a maneira como suas instituições sociais e econômicas evoluem; as "forças de reajustamento" das instituições em qualquer comunidade industrial moderna são principalmente econômicas. Nesse mesmo sentido, Schumpeter (1961, p. 32) afirma que: “[...] os homens escolhem sua maneira de agir, que não é diretamente imposta pelos dados objetivos do ambiente. Mas a escolha é feita com base em princípios, opiniões e propensões que não formam um conjunto de dados independentes, mas são, eles próprios, moldados pelo conjunto objetivo." Desse modo, os aspectos econômicos afetam e são afetados pelos fatores não econômicos, ainda que não no mesmo sentido e intensidade, além de a relação de causalidade não ser linear nem predeterminada.

Assim como as mudanças estruturais, identificadas no conceito de desenvolvimento econômico de Schumpeter (1997), as mudanças institucionais afetam o desempenho das economias, influenciando os ritmos e os rumos de tais transformações, ou seja, a forma como o crescimento econômico é acompanhado de outras mudanças que, em conjunto, permitem a ocorrência do desenvolvimento no longo prazo.

Isso leva ao entendimento de que as instituições estão sempre em evolução, sendo os agentes econômicos condicionados pela sua própria trajetória ao mesmo tempo em que desenvolvem a capacidade de promover transformações. Essas transformações, ou mudanças, não são necessariamente para melhor, pelo contrário, as "instituições imbecis" (Veblen, 1965) podem ser tão importantes e duradouras (inércia) ${ }^{20}$ quanto as demais.

Em se tratando de ações coletivas, Nelson e Winter (2005, p. 115) entendem que existe uma analogia entre o comportamento individual e as rotinas das organizações ${ }^{21}$. "Deve-se, portanto, esperar que as regularidades do

(20) Segundo Veblen (1965, p. 180), “[...]os hábitos mentais dos homens hodiernos tendem a persistir indefinidamente, exceto quando as circunstâncias obrigam a uma mudança. Essas instituições assim herdadas, esses hábitos mentais, pontos de vista, atitudes e aptidões mentais, ou seja lá o que for, são, portanto, um elemento conservador; e este é um fator de inércia social, de inércia psicológica, de conservantismo".

(21) Nelson (2002, p. 21) propõe que a rotina seja um "conceito unificador" entre a abordagem "institucionalista" e a "evolucionária": "[...] the notion of a routine fits very well with the conceptualization of many institutional economists, if the concept is turned to characterize standardized patterns of human transaction and interaction more generally". 
comportamento individual tenham conseqüências, senão contrapartidas, no nível da organização"22. Essa é uma das características analíticas que distingue os institucionalistas-evolucionários da NEI, uma vez que, esta última abordagem, ao ignorar o mecanismo de reconstitutive downward causation, se liga ao individualismo metodológico.

Esse mecanismo (regularidades) não deve ser confundido com "inércia institucional" (o que não implica descartar a importância da mesma), pois faz parte do processo de aprendizado, que inclui o mecanismo de "[...] unlearning by breaking down redundant institutions and eliminating obsolete conceptions and antiquated shared beliefs" (Maskell; Törnquist, 2003, p. 136). Como observa Hodgson (1999), o conhecimento (tácito e codificado) não depende tão somente da capacidade intelectual do indivíduo, mas da sua interação com outros indivíduos em um determinado ambiente, pois o processo de aprendizado é um fenômeno coletivo. Portanto, faz-se necessário dotar os indivíduos e as organizações de um ambiente favorável ao aprendizado e, por conseguinte, à inovação.

Os fatores institucionais afetam e são afetados, consequentemente, pelos fatores estruturais (inovações tecnológicas, organizacionais etc.), e é nesse sentido que promovem a mudança econômica numa perspectiva "institucionalistaevolucionária". Nessa abordagem, de forma distinta da proposta por North (1993) e incorporada à TCT, entende-se que as instituições devem ser consideradas sob a forma de "regras do jogo", mas também sob a forma de organizações, tais como as empresas em sua busca incessante pela inovação.

\subsection{A empresa como instituição e como unidade de análise}

Assumir a diversidade de tipos e de comportamentos das empresas como regra (Schumpeter, 1961; Penrose, 2006) transformou-se num ponto de partida fundamental para a argumentação "evolucionária"(neo-schumpeteriana) sobre a dinâmica econômica agregada. Considerar as diferentes "faces" da empresa, como instituição, tem se constituído no núcleo da análise em relação aos efeitos do seu comportamento sobre o desempenho das diferentes economias ${ }^{23}$.

(22) Nelson e Winter (1982, cap. 4) associam o desenvolvimento de habilidades individuais e das rotinas organizacionais como processos que contribuem diretamente para a construção do conhecimento tácito.

(23) Uma contribuição fundamental de Penrose está justamente na ênfase que a autora dedica aos aspectos relativos ao funcionamento interno da empresa (num contexto em que a empresa era concebida na esfera econômica, predominantemente, como uma "caixa preta"), a partir de uma abordagem econômica dos fatores que determinam o seu comportamento e a sua expansão em função do uso de recursos materiais e humanos e da importância do conhecimento relacionado às atividades produtiva, administrativa e empreendedora. Conforme Penrose (2006, p.230): “[...] a firma constitui essencialmente um reservatório de recursos cuja utilização é realizada por meio de um arcabouço administrativo". Nesse sentido, a autora destaca a necessidade da análise da empresa tanto a partir de seu interior quanto da forma como essa utiliza os seus "recursos disponíveis" para atuar frente à concorrência no mercado, ambos considerados "instituições" em transformação permanente e interligada. 
Por mais que uma empresa empregue estratégias conscientes para guiar suas ações, sempre haverá algum grau de subjetividade no tratamento da realidade em função da incerteza e da racionalidade limitada dos agentes. Como observam Nelson e Winter (2005, p.64), “[...] o mundo econômico é por demais complicado para que a firma o compreenda perfeitamente [...]”. Com base nessa observação, o resultado do processo de busca e seleção é que dirá em que medida a empresa adotou uma estratégia compatível com a realidade observada a partir das suas próprias condições produtivas, organizacionais e institucionais, ou seja, a partir das suas condições internas e da sua interatividade.

À medida que optam por uma determinada estratégia tecnológica, as empresas precisam criar condições organizacionais compatíveis para tornála viável. Nesse sentido, a inovação tecnológica está diretamente associada às inovações organizacionais e institucionais ao criar diferentes formas de interação da empresa com o ambiente em que se insere e dos indivíduos em seu interior. As transformações econômicas têm sido caracterizadas pela "coevolução" de fatores estruturais (tecnológicos e organizacionais) e institucionais (Nelson, 1998), o que evidencia que as inovações compreendem um escopo bem mais complexo do que o avanço tecno-produtivo; além disso, o fato de as tecnologias serem "físicas e sociais" (Nelson, 2002) demonstra que a ação das empresas extrapola o seu ambiente produtivo (organização) e transacional (trocas). A partir desse processo, em permanente modificação, surgem e se desenvolvem o que Langlois e Robertson (1995, p.1) definem como "instituições empresariais": "[...] a productive routine, a habitual pattern of behaviour embodying knowledge that is often tacit and skilllike."

Em relação aos aspectos internos da empresa, Nelson e Winter (2005) ressaltam que inovação e rotina não são "ideias opostas". Ao contrário, a rotina das empresas pode tornar-se a base do processo de inovação, seja na solução de problemas, seja no desenvolvimento de novas maneiras de se fazer algo, tendo caráter dinâmico à medida que caracteriza mudança, não se tratando, portanto, de pura e simples repetição, mas sim de acumulação de conhecimentos. A rotina não levaria à perfeição, mas à transformação.

Nesse sentido, organizações (como as empresas) possuem um conjunto de mecanismos que possibilitam a reprodução de hábitos e rotinas ${ }^{24}$, exercendo um importante papel sobre o comportamento dos indivíduos em seu interior, mas também fora dele. Segundo Hodgson (2007, p. 110): “Organizations are bounded institutions with a relatively high degree of cohesion. Their characteristics of

(24) "Routines are organizational dispositions to energize conditional patterns of behaviour within an organized group of individuals, involving sequential responses to cues. [...] Organizational routines depend upon a structured group of individuals, each with habits of a particular kind, where many of these habits depend upon procedural memory" (Hodgson, 2007, p. 110). 
membership, sovereignty and responsibility enhance the possibilities for more intensive interactions between individuals and organizations."

Seja através de regras formais ou informais, as organizações criam uma estrutura social e um ambiente físico no qual os indivíduos estão inseridos e a partir do qual moldam os seus hábitos de pensamento e ação, transformando-os em rotinas. "Individuals have habits; groups have routines. [...] Routines are irreducible to habits alone: they are organizational meta-habits, existing on a substrate of habituated individuals in a social structure" (Hodgson, 2007, p. 111). As rotinas caracterizam a situação em que os hábitos se transformam em regras (formais e informais), organizadas e seguidas institucionalmente, sendo, por isso, fundamentais para o desenvolvimento do processo de aprendizado.

As rotinas e as capacitações definem as especificidades/particularidades de cada empresa, de modo que "[...] any other firm would possess exactly the same traits, competences, and behavior patterns"(Langlois; Robertson, 1995, p. 17). É por esse motivo que, conforme Teece e Pisano (1994, p. 553), “[...] capabilities generally cannot be bought; they must be built".

Para Langlois e Robertson (1995, p. 14-16), rotinas e capacitações têm significados diferentes, mas complementares: "[...] routines refer to what an organization actually does, while capabilities also include what it may do if its resources are reallocated. [...] capabilities refer to the skills, experience, and knowledge that a firm possesses". O significado desses conceitos é fundamental para a compreensão da importância dos indivíduos para as organizações, o que, em grande medida, explica a variedade de empresas no mercado, com diferentes estratégias, mesmo que dentro de um mesmo ramo produtivo.

As capacitações e competências organizacionais da firma são fundamentais para determinar os seus resultados, tanto no que se refere a sua lucratividade e crescimento quanto a sua probabilidade de sobrevivência ${ }^{25}$. De acordo com Coriat e Dosi (2002), duas questões fundamentais devem ser levadas em consideração para a compreensão da "natureza das competências/capacitações organizacionais": o contexto em que as organizações estão inseridas e a forma como afetam as habilidades e o conhecimento de seus membros.

(25) Para Coriat e Dosi (2002), apesar do uso frequente desses vocábulos como sinônimos, "capacitação" e "competência" têm diferentes significados como processos fundamentais para a performance da empresa. Tratase de dois resultados de um conjunto de mecanismos que, ao se inter-relacionarem, de certo modo, acabam sendo confundidos. Tentando esclarecer a diferença, esses autores afirmam que "capacitação" tem um sentido mais amplo, compreendendo as "rotinas organizacionais" no que se refere a seus aspectos estritamente repetitivos, bem como às "ações conscientes" e ao desenvolvimento de habilidades individuais, mas, sobretudo, organizacionais. O termo “competência”, por sua vez, estaria mais relacionado aos mecanismos de intermediação entre rotinas e capacitações, “[...] capturing 'chunks' of organizational abilities identified in terms of performed tasks and knowledge-bases upon which they draw" (Coriat; Dosi, 2002, p. 284). De qualquer forma, os autores entendem que não há problemas em relação ao "uso análogo" de capacitações e competências, desde que se compreenda o seu significado para a análise das organizações. 
Em síntese, a empresa é a unidade central da análise em virtude de se constituir no locus principal da geração (em um processo de "destruição criativa" via acumulação de conhecimentos), adaptação e uso das inovações e do processo de aprendizado como eventos coletivos (organizacionais). Disso resultam duas conclusões evolucionárias fundamentais: primeiro, a de que a inovação tecnológica é fator fundamental para a mudança econômica e, segundo, a de que o ambiente com o qual a empresa interage em sua "luta pela sobrevivência" exerce uma forte influência sobre o seu comportamento inovativo e competitivo. O comportamento adaptativo, que estabelece as bases do processo de seleção, é resultado dessa dinâmica caracterizada por constantes transformações na qual a empresa também desempenha um papel fundamental quando se trata de inovações organizacionais e institucionais. Nesse sentido, as "instituições empresariais" desempenham um papel primordial na mudança econômica, indo além de meras unidades produtivas e transacionais que tomam decisões em um dado contexto, como será visto a seguir.

\section{A empresa e seus ambientes de interação em uma Teoria Institucionalista Evolucionária da firma: para além da Teoria dos Custos de Transação}

Para Pondé (2002, p. 298), a abordagem "evolucionária” compartilha com a "teoria dos custos de transação" (TCT) duas características: concebem a empresa como sendo organizada a partir de um "[...] conjunto de arranjos institucionais qualitativamente distintos daqueles presentes nos mercados [...]"; e adotam uma "abordagem essencialmente comparativa" à medida que procuram analisar as mudanças que ocorrem ao longo do tempo, num ambiente competitivo, em relação à própria empresa e a outras empresas que se encontram no mercado. Apesar dessas similaridades, o autor sugere que, para romper com os limites da TCT, essa deveria ser incorporada a uma teoria mais "geral do processo de concorrência" (evolucionário) em que a compreensão da organização e da ação empresarial se desse de forma dinâmica.

Isso posto, estabelecem-se algumas diferenças fundamentais que demonstram os limites da abordagem teórica da NEI, com ênfase nos custos de transação, ao passo que a Teoria Institucionalista Evolucionária, mais abrangente e complexa, abarca um conjunto mais significativo de fatores que relacionam mudanças estruturais (sobretudo tecnológicas) e institucionais, e seus efeitos sobre o desempenho das economias, inclusive no que se refere aos custos de transação (dinâmicos) e à "estrutura de governança".

Essas diferenças começam pela compreensão do mercado, considerado uma instituição fundamental do capitalismo nas abordagens institucionalistas, mas que aparece, na teoria da NEI, como um dado (estático) a partir do qual os agentes tomam 
suas decisões. Para a NEI, a racionalidade limitada, a incerteza e o oportunismo ${ }^{26}$, ao definirem os custos de transação, acabam estabelecendo em que medida o mercado e as instituições vigentes podem ser considerados eficientes no sentido produtivo e distributivo. Assumir que a empresa é um agente tomador de decisão, cujo objetivo central passa pela redução dos custos de transação, estabelece uma dicotomia entre mercados e empresas, como se as relações entre essas duas instituições capitalistas fossem essencialmente criadas e desenvolvidas para realizar atividades de troca e de alocação dos fatores produtivos. Há uma falsa dicotomia na compreensão de que a empresa é a antítese do mercado numa economia capitalista.

Por sua vez, compreender o mercado numa perspectiva institucionalista evolucionária implica descaracterizá-lo tanto como "ente abstrato" quanto como um "dado" a partir do qual os agentes tomam as melhores decisões possíveis. Trata-se de uma instituição e, como tal, é resultado de um processo histórico de interação com os indivíduos e as organizações. As instituições são interligadas e altamente integradas, e a influência mútua condiciona suas trajetórias. Isso é válido para a relação entre empresas e dessas com os mercados.

As escolhas dos indivíduos e das organizações frente ao mercado são condicionadas por um conjunto de fatores que envolve desde o sentido das informações (assimétricas ou não), passando pelo processo de educação e socialização, resultando no desenvolvimento da capacidade cognitiva. Isso significa que os indivíduos e as empresas têm o seu comportamento socialmente condicionado e, nesse sentido, suas escolhas dependem de um conjunto de fatores que vão além da capacidade de ação isolada (Hodgson, 1994, 2002).

As formas de controle e organização da economia compreendem um sistema bem mais amplo e complexo do que o mercado. As trocas ocorrem tanto dentro quanto fora do mercado, considerando a existência de instituições formais e informais que condicionam esse processo. Conforme Samuels (1995, p. 571), a abordagem evolucionária rejeita a ideia de que o mercado é um mecanismo que guia e organiza a economia: "[...] markets are organised by and give effect to the institutions which form them". Ou, conforme Hodgson (1999, p. 243): "Markets are specially developed and institutionalized groups of exchanges, involving measures to structure, organize and legitimate such transactions" ${ }^{\prime 27}$.

(26) Para Hodgson (1994), o principal problema em assumir o oportunismo como um pressuposto válido é que, ao ser um "modelo individualista da natureza humana", não leva em consideração a importância dos efeitos exercidos pelo ambiente institucional sobre os hábitos de pensamento e as ações dos indivíduos. Nesse sentido, o pressuposto do oportunismo é reducionista.

(27) Para Dunning (1997, p. 37), “[...] markets are not a free good; they cost resources to set up, to operate and to maintain. They also mean that governments need to recognize that the efficiency of many markets [...] is not solely determined by the transaction of the buyers and sellers in those markets, but by a host of other factors, including the action taken by other governments, over which they may have no immediate influence or control." 
Nesse sentido, longe de se apresentar como um locus imparcial, as "estruturas e convenções" do mercado revelam a sua influência sobre o comportamento dos indivíduos, bem como a importância das ações das empresas no seu funcionamento. A própria empresa pode ser explicada como uma "instituição de poder", e não pela sua eficiência na redução dos custos de produção e transação (Hodgson, 1994) ${ }^{28}$.

A TCT considera a mudança de forma impessoal, como se as empresas tivessem um comportamento similar frente ao mercado (redução de custos e maximização), ao passo que a abordagem institucionalista evolucionária, sobretudo no que se refere à rotina e ao aprendizado, ressalta o caráter idiossincrático da mudança.

$\mathrm{Na}$ perspectiva institucionalista evolucionária, as capacitações organizacionais (fruto do aprendizado) determinam o comportamento da empresa e, por conseguinte, o ritmo e os rumos da mudança a partir de sua interação com as demais instituições. Como observa Dosi (2006, p. 160): “A cada momento no tempo, para cada empresa específica, o ambiente externo é dado e define o conjunto de restrições para seus comportamentos. Esses comportamentos e suas interações, por sua vez, mudam os ambientes externos." Ou seja, a essência do processo não está baseada na dicotomia, e sim na interação entre empresas e mercados.

Considerar que o mercado coordena apenas transações implica que relações, como as de aprendizado, seriam estabelecidas através de mecanismos extra mercado, demonstrando que a empresa, como "instituição que aprende", tem suas ações apenas parcialmente condicionadas pelos fatores transacionais como forma determinante do seu comportamento (Edquist, 2001). Nesse sentido, conforme a TCT, haveria uma dicotomia entre empresa e mercado, e não um processo de aprendizado interativo..

Corroborando o exposto anteriormente, Hodgson $(1993,1998)$ afirma que parte dos autores da NEI ainda adota a concepção neoclássica de que o mercado é um "dado natural", uma agregação de indivíduos e empresas, que, no máximo, possui imperfeições; ainda assim, como instituição fundamental, costumaria conduzir à maior eficiência e ao crescimento econômico. Considerando-se a afirmação de Williamson (apud Hodgson, 1998, p. 182) de que "[...] in the beginning there were markets[...]", presume-se que os agentes se posicionam diante da "instituição mercado", tomando decisões conforme sua racionalidade limitada e seu oportunismo, ainda que com restrições e incerteza. Para a NEI, o mercado faz parte das "regras do jogo", não se configurando como um espaço de interação entre as empresas e o próprio mercado, sob a influência do Estado, o que teria condicionado a sua formação nas diferentes economias capitalistas.

(28) Hodgson (1994) ressalta que a NEI confunde, a exemplo da teoria econômica neoclássica, existência com eficiência, ignorando os motivos que levam empresas ineficientes a existirem durante longos períodos de tempo em função da influência que exercem sobre os mercados em que atuam. 
Uma das funções das instituições econômicas, para a NEI, consiste em ajustar o funcionamento do mercado para minimizar os custos de transação, garantindo, com isso, uma maior eficiência do sistema econômico. Assim, o desempenho econômico estaria condicionado ao "bom" funcionamento do mercado (Villeval, 1995). Para decidir se é melhor produzir internamente (make) ou optar pelo mercado (buy), é necessário um pleno conhecimento do seu funcionamento, à medida que a empresa considere os custos de transação e de produção. Tal perspectiva da NEI não é compatível com a ideia de que o mercado possui forças equilibradoras e desequilibradoras, ambas endógenas.

Na concepção institucionalista evolucionária, a admissão da existência de falhas de mercado é um "ponto de partida enganoso" (Cimoli et al., 2007), sendo por isso que outras instituições são consideradas fundamentais para a promoção do desenvolvimento econômico. Ao mesmo tempo, esse mercado se apresenta como uma estrutura de poder

Em se tratando da organização da empresa, a aceitação da teoria neoclássica (nível L4 do "modelo de análise social"), ao contrário do que defende Williamson (2000), não tem contribuído para a compreensão das atividades internas da empresa, limitando o escopo de análise das inovações organizacionais. Faz-se necessário romper com os pressupostos neoclássicos para compreender a empresa como uma "organização que aprende" ou como uma instituição, e não como uma "função de produção", ainda que se trate apenas de aspectos produtivos no curto prazo. Assim, o nível L4 do modelo de Williamson (2000) não é um nível de "análise social"; trata-se de uma abstração a respeito do funcionamento da empresa, que reforça a importância da escolha e da alocação produtiva (fatores estáticos). Nesse sentido, não surpreende que o autor tenha dificuldades de relacionar o nível L4 com o L3, como propõem as setas do modelo.

Conforme a perspectiva institucionalista evolucionária, é um equívoco separar a análise da estrutura produtiva das instituições que lhe dão suporte. Como observa Reinert (2007), as instituições são parte integrante e indissociável de um determinado sistema produtivo, independentemente de quão desenvolvido e avançado tecnologicamente seja o país. Dissociar os fatores institucionais dos produtivos implica compreender que a empresa é um agente tomador de decisão, em vez de uma instituição que interage, afeta e é afetada pelo ambiente em que está inserida. Na perspectiva institucionalista evolucionária, existe um ganho, representado pela economia de recursos cognitivos (aprendizado através da rotina etc.) que é path-dependent e também firm-specific, estando estreitamente vinculado à estrutura institucional vigente.

As diferentes formas de manifestação da concorrência (Possas, 2002) demonstram que a variável custos (produção e transação) é fundamental, obviamente, 
ainda que insuficiente para explicar o funcionamento da empresa e sua interação com o mercado. Nesse mesmo sentido, Hodgson (1994, p. 207) afirma que, “[...] embora esclarecedor, o conceito de custos de transação não constitui base suficiente para uma teoria sobre a natureza da empresa". Ao centrar sua abordagem nos custos de transação, a NEI simplifica equivocadamente a análise das empresas como organizações, ainda que considere as "estruturas de governança" que, por sua vez, são fortemente influenciadas pela necessidade de economizar por parte da empresa.

Para North (1993), diferentemente do que propõe a TCT, além de afetarem os custos de transação, as instituições desempenham papel fundamental sobre os custos de produção à medida que exercem influência direta sobre a alocação dos recursos produtivos e sua transformação em bens e serviços. Ainda que a tecnologia seja fundamental, tanto para a redução dos custos de transação quanto de produção, a decisão sobre o seu uso está relacionada à "estrutura institucional", em que as escolhas dos agentes importam mais do que o processo de geração da tecnologia (e do aprendizado envolvido) como resultado da trajetória econômica.

Segundo Hodgson (1999), um dos equívocos de Coase (1999) e Williamson (1989a) foi conceber a produção capitalista essencialmente como uma alocação de recursos produtivos a partir de decisões sobre a transação. Na abordagem institucionalista evolucionária, diferentemente, é dada ênfase ao processo criativo e às formas de aprendizado, que condicionam a alocação e a transformação dos recursos produtivos, sobretudo daqueles vinculados ao conhecimento, os quais aumentaram sua importância contemporaneamente.

Se os objetivos das empresas são variados, é compreensível que várias sejam também as suas dimensões no que se refere ao seu comportamento e desempenho. Não se trata de conceber a existência da empresa a partir de um somatório de custos (produção e transação), ainda que com pressupostos relaxados, mas sim de considerar a diversidade interna (organização) e externa (mercado) em que a empresa constrói a sua trajetória.

Na visão institucionalista evolucionária, a "racionalidade" do sistema é mais importante do que a "racionalidade" individual, o que significa, por um lado, que não necessariamente a tecnologia mais eficiente vá prosperar e, por outro, que as empresas (em seu ambiente), e não os indivíduos, sejam os principais tomadores de decisão. Isso contrasta com a perspectiva reducionista (individualismo metodológico) da abordagem dos custos de transação, sobretudo no que se refere aos pressupostos da maximização e do oportunismo adotados por Williamson.

A necessidade de predição (capacidade de prognóstico), presente nos trabalhos de Coase e, sobretudo, nos de Williamson, abordada nesta seção, é fortemente influenciada pelo neoclassicismo econômico e acaba condicionando a construção teórica da NEI no que se refere à importância da escolha do mercado 
como forma de evidenciar um comportamento maximizador dos agentes ${ }^{29}$. Além disso, para Williamson (1989a, 1995, 2000), as transformações são necessariamente positivas, na medida em que há uma opção por menores custos totais por parte dos agentes, em um determinado ambiente institucional, que levariam à construção de instituições mais eficientes, influenciando positivamente o desempenho das economias.

Admitir a hipótese de maximização implica pressupor que a opção pelo mercado demonstra que esse é mais eficiente no sentido de que reduz os custos totais. Entretanto, só é possível presumir a eficiência do mercado a partir do pressuposto de que há uma ordem preestabelecida, em que o conflito, normalmente gerado pelo exercício do poder (político e econômico), não é relevante o suficiente para afetar o ambiente institucional. Nesse caso, o pressuposto da maximização torna-se teleológico, já que a mudança institucional deve ser incremental e positiva; caso não seja, é porque o comportamento dos agentes não foi maximizador. A maximização ex ante explicaria a maximização ex post. Em suma, a necessidade de predição caracteriza a teleologia do pressuposto da maximização; constituindo-se não só em um objetivo, mas também em um resultado previsível. Além disso, a maximização é um pressuposto reducionista, porque centra na ação individual (oportunista) a análise do desenvolvimento das instituições e do desempenho das economias.

Ao rejeitar o pressuposto da maximização, Nelson e Winter (2005) entendem que é através das rotinas que a empresa constrói suas estratégias e atinge seus resultados. A natureza evolutiva da empresa implica que as rotinas não conduzem à maximização, como uma condição ex ante ou como um objetivo ex post, mas sim a uma trajetória específica em que cada empresa desenvolve ou não condições para permanecer no mercado.

Para Nelson e Winter (2005, p. 55), assumir que o "lucro é o único objetivo empresarial explicitamente reconhecido", ou seja, que se trata de uma busca da empresa via inovação, é essencialmente diferente de assumir o pressuposto ortodoxo da maximização do lucro (máxima receita possível de ser obtida a partir do sistema de preços de mercado e dos custos de produção e de transação da empresa) ${ }^{30}$. A

(29) North (1993, p. 108) diverge dessa concepção ao afirmar que: "En un mundo de incertidumbres nadie conoce la manera correcta de resolver los problemas que enfrentamos y nadie puede, en efecto, maximizar utilidades." Simon (1991, p. 26) questiona em que medida os empregados estariam alinhados aos interesses dos empregadores na busca da maximização dos lucros: “Why do employees often work hard?". Para Simon, a existência de contratos não garante a unidade de interesses. Conforme Lazonick (2007), formas de compensação, tais como promoção e outros benefícios, são importantes instrumentos para manter os indivíduos integrados à organização, contribuindo diretamente para o processo de aprendizado, o que não caracterizaria um comportamento maximizador, seja por parte dos indivíduos ou das organizações.

(30) A abordagem institucionalista-evolucionária adota o pressuposto, desenvolvido por Herbert Simon, de que a empresa, ao invés de ter um comportamento maximizador, procura reunir condições para obter "resultados satisfatórios" (satisficing), em função dos propósitos que movem suas ações (lucro, aumento da competitividade, conquista de mercado etc.). 
maximização pressupõe o pleno conhecimento da capacidade de ação e reação da empresa em relação ao presente e ao futuro, eliminando as dificuldades de capacidade decisória em relação à atividade econômica, ao passo que o "lucro como objetivo" pressupõe a remuneração do investimento produtivo, que condiciona a sobrevivência da empresa em um ambiente competitivo e instável.

Apesar do esforço da abordagem da NEI para demonstrar que o mainstream não trata mais a economia de forma estacionária, no sentido de que considera o processo de transformação, a perspectiva reducionista, que permanece na TCT, revela que a causação do processo de mudança tem uma tendência à linearidade, pois há um elevado grau de previsibilidade no comportamento dos indivíduos, considerados os agentes centrais da mudança. Dessa forma, o mercado é mais um locus de ação do que propriamente uma instituição, como defendem os autores que partem da transação como unidade de análise.

Na perspectiva institucionalista evolucionária, o mercado é uma instituição que se transforma através da interação com os agentes (Estado, empresas e indivíduos). Para a NEI (exclusive para Douglass North) ${ }^{31}$, ao contrário, trata-se de uma instituição diante da qual os agentes adotam uma postura reativa. Edquist (2001) ressalta que tanto as transações de mercado quanto as que ocorrem fora dele são fundamentais para o processo de inovação (produto, processo e organizacional), o que contrasta com a TCT, para a qual o mercado (a transação) é o determinante principal do comportamento da empresa, sobretudo no que diz respeito à mudança organizacional (governance).

A incorporação do conceito de custos de transação por parte da abordagem institucionalista evolucionária, ao mesmo tempo que ressalta sua importância para a análise do comportamento da empresa, deixa evidente os seus limites. A explicação híbrida ou plural (Hodgson, 1999) para a existência da empresa reforça a importância dos custos de transação, mas dá ênfase a sua expressão dinâmica, a exemplo dos demais fatores, ao contrário da abordagem essencialmente estática da NEI. Considerando a empresa como uma "instituição produtiva e de aprendizado", tem-se, nos custos de transação, apenas um dos fatores que determinam o seu funcionamento, não evidenciando, necessariamente, primazia sobre os demais.

$\mathrm{Na}$ medida em que os mercados não funcionam conforme pressupõe a teoria neoclássica (dado natural), os custos de transação são afetados por um conjunto de fatores, inclusive pelo comportamento das empresas, sobretudo nas situações em que têm forte poder de mercado. Não se trata de minimizar a importância dos custos de produção e transação, mas sim de compreender que os mesmos são alterados conforme o funcionamento do mercado, que, por sua vez, é uma instituição condicionada

(31) De acordo com Nelson (2002, p. 19), “Douglass North (1990), perhaps today's best known economic 'institutionalist', gradually has adopted an evolutionary perspective regarding how institutions form and change." 
por um conjunto de fatores de natureza econômica e política, a exemplo da matriz institucional do Estado.

A concepção de mercado, na perspectiva institucionalista evolucionária, evidencia um conjunto de fatores que, de alguma forma, está diretamente relacionado ao funcionamento da empresa como instituição. Ou seja, não é possível tratar de estratégias empresariais sem reconhecer a influência do ambiente em que elas são adotadas. Nessa perspectiva, as empresas são afetadas, mas também afetam o funcionamento dos mercados em que se inserem, sobretudo quando se trata de grandes corporações. Desse modo, só é possível entender o desempenho das empresas quando se consideram os mercados em que atuam.

Por sua vez, a geração e a apropriação dos resultados da inovação implicam, necessariamente, a existência de assimetrias de conhecimentos. Esses conhecimentos são práticas internalizadas, fundamentais para o processo de mudança, que não envolvem custos de transação, dado que não há a opção pelo uso do mercado. A abordagem da TCT, nesse caso, está vinculada ao pressuposto (neoclássico) de que o conhecimento (reduzido à ideia de informação) é um bem comercializável. Essa inovação, a partir do processo de aprendizado, ainda que envolva diferentes empresas (cooperação), é resultado de aspectos idiossincráticos, que envolvem principalmente o componente tácito do conhecimento, que é firm-specific. Ou seja, a regra constitui-se nas assimetrias entre empresas a partir das suas diferentes capacitações tecnológicas e organizacionais resultantes de suas rotinas.

\section{Considerações finais}

Pode-se considerar que existe uma semelhança entre a TCT e a Teoria Econômica Institucionalista Evolucionária no que se refere à tomada de decisão a partir de informações incompletas e da racionalidade limitada dos agentes. No entanto, na TCT, há o pressuposto de que a construção de regras permite o acerto das previsões, em média, em relação aos resultados futuros, ao passo que, para a visão institucionalista evolucionária, a incerteza é suficientemente relevante para não garantir previsões acertadas. Em suma, apesar de estarem presentes nas duas abordagens, assimetria de informação, racionalidade limitada e incerteza, de forma combinada, produzem diferentes resultados, dependendo da perspectiva de análise (custos de transação ou empresa como unidade de análise).

Concentrar a análise nos custos de transação subestima a complexidade das relações que envolvem as empresas em seus diferentes ambientes (interno e externo) de interação. Nesse sentido, a TCT, ao enfatizar o funcionamento da empresa a partir de seus limites de atuação frente ao mercado, restringe o seu papel ao de um agente econômico, quando, de fato, se trata de uma instituição capitalista com elevado grau de responsabilidade pelas transformações econômicas. 
Na Teoria Econômica Institucionalista Evolucionária, as empresas possuem um papel destacado no processo de desenvolvimento das diferentes economias, considerando as singularidades de suas trajetórias. Por esse motivo, não são tomadas apenas como agentes econômicos, mas também como instituições fundamentais nos processos de mudança por se constituírem nos principais promotores das inovações tecnológicas (físicas e sociais).

$\mathrm{Na}$ medida em que a coevolução de tecnologias (físicas e sociais), estruturas econômicas (produtivas, organizacionais, comerciais etc.) e instituições condicionam o desempenho das economias capitalistas, as instituições empresariais, a partir de suas diferentes formas de interação, passam a ser um objeto de estudo mais adequado à apreensão da mudança permanente. Desse modo, compreender a trajetória das empresas como instituições inovativas a partir do acúmulo de conhecimentos (refletido nas competências e capacitações organizacionais) torna-se fundamental para a análise do seu papel no desempenho das diferentes economias.

Nesse sentido, entende-se que a construção de uma "teoria da firma institucionalista evolucionária" requer a consolidação de conceitos como rotina (genes), aprendizado (interação), adaptação (seleção) e crescimento (evolução) em sua abordagem para uma compreensão mais adequada dos fenômenos econômicos associados ao comportamento das empresas que, num contexto capitalista, têm sido concebidas como "instituições inovativas" por excelência. Para tanto, conceber as empresas como instituições significa incorporá-las de forma mais rica à teoria econômica. Uma teoria da firma com esse caráter, e que considere inclusive os custos de transação e as "estruturas de governança" (contribuição originária da NEI), é fundamental para a "Teoria Institucionalista Evolucionária". Nesse sentido, ela se constitui em um referencial mais adequado para analisar as singularidades que abrangem o desenvolvimento econômico, considerando as empresas como agentes/ instituições fundamentais do processo de transformação.

\section{Referências bibliográficas}

ATKISON, G.; OLESON, T. Institutional inquiry: the search for similarities and differences. Journal of Economic Issues, v. XXX, n. 3, p. 701-18, Sept. 1996.

CHANG, H-J. Globalisation, economic development and the role of the state. London and New York: Zed Books, 2004.

. Understanding the relationship between institutions and economic development - some key theoretical issues. In: CHANG, H-J. (Ed.). Institutional change and economic development. New York: United Nations University Press, 2007.

CIMOLI, M.; DOSI, G.; NELSON, R. R.; STIGLITZ, J. Instituições e políticas moldando o desenvolvimento industrial: uma nota introdutória. Revista Brasileira de Inovação, v. 6, n. 1, p. 55-85, jan./jun. 2007. 
COASE, R. H. The Institutional structure of production. The American Economic Review, v. 82, n. 4, p. 713-719, Sept. 1992.

The nature of the firm. In: WILLIAMSON, O. E.; MASTEN, S. E. (Ed.). The economics of transaction costs. Cheltenhan, UK; Northampton, MA, US: Elgar Critical Writings Reader, 1999. p. 3-22.

COMMONS, J. R. Institutional economics. The American Economic Review, v. 21, p. 648657, 1931.

CONCEIÇÃO, O. A. C. Instituições, crescimento e mudança na ótica institucionalista. Porto Alegre: FEE, 2001. (Teses FEE, n. 1).

CORIAT, B.; DOSI, G. The nature and accumulation of organizational competences/ capabilities. Revista Brasileira de Inovação, v. 1, n. 2, p. 275-326, jul./dez. 2002.

DOSI, G. Mudança técnica e transformação industrial: a teoria e uma aplicação à indústria de semicondutores. Campinas: Unicamp, 2006.

; MALERBA, F. Organizational learning and institutions embeddedness: an introduction to the diverse evolutionary paths of modern corporation. In: DOSI, G.; MALERBA, F. (Ed.). Organization and strategy in the evolution of enterprise. Macmillan Press, 1996. p. 1-24.

DUNNING, J. H. Alliance capitalism and global business. London and New York: Routledge, 1997.

EDQUIST, C. The systems of innovation approach and innovation policy: an account of the state of the art. DRUID Conference, Aalborg University, Jun., 12-15, 2001.

ESPINO, J.A. Instituciones y economía:unaintroducción al neoinstitucionalismo económico. México: Fondo de Cultura Económico, 1999.

HODGSON, G. M. Institutional economics: surveying the 'old' and the 'new'. Metroeconomica, v. 44, n. 1, p. 1-28, 1993.

. Economia e instituições: manifesto por uma economia institucionalista moderna. Oeiras: Celta Editora, 1994.

From micro to macro: the concept of emergence and the role of institutions. International seminar "Institutions and Economic Development: Towards a Comparative Perspective on State Reform”. Rio de Janeiro: UFRJ, Brazil, 12-14 nov. 1997.

. The approach of institutional economics. Journal of Economic Literature, v. 36, p. 166-192, mar. 1998.

. Evolution and institutions: on evolutionary economics and the evolution of economics. Cheltenham, UK; Northampton, MA, USA: Edward Elgar, 1999.

The evolution of institutions: an agenda for future theoretical research. Constitutional Political Economy, n. 13, p. 111-127, 2002. 
HODGSON, G. M. What are institutions? Journal of Economic Issues, v. XL, n. 1, p. 1-25, Mar. 2006.

Institutions and individuals: interaction and evolution. Organization Studies, v. 28, n. 1, p. 95-116, Jan. 2007.

LANGLOIS, R. N.; ROBERTSON, P. L. Firms, markets and economic change - a dynamic theory of business institutions. London and New York: Routledge, 1995.

LAZONICK, W. Corporate governance, innovative enterprise and economic development. In: CHANG, H-J. (Ed.). Institutional change and economic development. New York: United Nations University Press, 2007. Chapt. 7, p.115-133.

MASKEL, P.; TÖRNQUIST, G. The role of universities in the learning region. In: RUTTEN, R.; BOEKEMA, F.; KUIJPERS, E. (Ed.). Economic geography of higher education: knowledge infrastructure and learning regions. London and New York: Routledge, 2003. p. 129-144.

MATTHEWS, R. C. O. The economics of institutions and the sources of growth. The Economic Journal, n. 96, p. 903-918, Dec. 1986.

NELSON, R. R. Bringing institutions into evolutionary growth theory. Journal of Evolutionary Economics, v. 12, n. 1-2, p. 17-28, Mar. 2002.

Economic development from the perspective of evolutionary economic theory. Governance and Economic Dynamics, 2006. (Working Papers in Technology, n. 2)

NELSON, R. R.; WINTER, S. G. Uma teoria evolucionária da mudança econômica. Campinas: Editora da Unicamp, 2005.

NORTH, D. C. Institutions. The Journal of Economic Perspective, v. 5, n. 1, p. 97-112, Winter 1991.

Instituciones, cambio institucional y desempeño económico. México: Fondo de Cultura Económico, 1993.

Economic performance through time. The American Economic Review, v. 84, p. 359-369, Jun. 1994.

Understanding the process of economic change. Princeton and Oxford: Princeton University Press, 2005.

Custos de Transação, instituições e desempenho econômico. 3. ed. Rio de Janeiro: Instituto Liberal, 2006.

PENROSE, E. A teoria do crescimento da firma. Campinas: Editora da Unicamp, 2006.

PONDÉ, J. L. Organização das grandes corporações. In: KUPFER, D.; HASENCLEVER, L. (Org.). Economia industrial: fundamentos teóricos e prática no Brasil. Rio de Janeiro: Elsevier, 2002. cap. 13, p. 287-306. 
POSSAS, M. Elementos para uma integração micro-macrodinâmica na teoria do desenvolvimento econômico. Revista Brasileira de Inovação, v. 1, Ano 1, p. 123-149, jan./ jun. 2002.

REINERT, E. S. Institutionalism ancient, old, and new: A historical perspective on institutions and uneven development. In: CHANG, H-J. (Ed.). Institutional change and economic development. New York: United Nations University Press, 2007. Chapt. 4, p. 53-72.

SAMUELS, W. J. The present state of institutional economics. Cambridge Journal of Economics, v. 19, p. 569-590, 1995.

SCHUMPETER, J. A. Capitalismo, socialismo e democracia. Rio de Janeiro: Fundo de Cultura, 1961.

. Teoria do desenvolvimento econômico: uma investigação sobre lucros, capital, crédito, juro e o ciclo econômico. São Paulo: Nova Cultural, 1997.

SIMON, H. A. Rationality in Psychology and economics. In: HOGARTH, R.; REDER, M. (Ed.). Rational choice. Chicago: Chicago University Press, 1987. p. 25-40.

Spring 1991.

. Organizations and market. Journal of Economic Perspective, v. 5, n. 2, p. 25-44,

TEECE, D. J.; PISANO, G. The dynamic capabilities of firms: an introduction. Industrial and Corporate Change, v. 3, n. 3, p. 537-556, 1994.

VEBLEN, T. B. A teoria da classe ociosa: um estudo econômico das instituições. São Paulo: Livraria Pioneira Editora, 1965.

VILLEVAL, M. C. Une théory economique des institutions. In: BOYER, R.; SAYLLARD, Y. Théory de la regulation: l'état des savoirs. Paris: La Découverte, 1995.

WILLIAMSON, O. E. Las instituciones económicas del capitalismo. México: FCE, 1989a.

. Transaction costs economics. In: SCHMALENSEE, R.; WILLIG, R. D. Handbook

of Industrial organization. Elsevier Science Publishers, 1989b. v. 1, p. 135-82.

- Transaction cost economics and organization theory. Industrial and Corporate Change, v. 2, n. 2, p. 107-156, 1993.

Hierarchies, markets and power in the economy: an economic perspective.

Industrial and Corporate Change, v. 4, n. 1, p .21-49, 1995.

. The institutions of governance. The American Economic Review, v. 88, n. 2, p. 75-79, May 1998.

. The New Institutions Economics: tacking stocks, looking ahead. Journal of Economic Literature, v. XXXVIII, p. 595-613, Sept. 2000. 